\title{
Expanding access to vasectomy services in the Ministry of Health of Guatemala
}

\author{
Blanca De Rodriguez \\ Ricardo Vernon \\ Population Council \\ Jorge Solorzano \\ Population Council
}

Follow this and additional works at: https://knowledgecommons.popcouncil.org/departments_sbsr-rh

Part of the Demography, Population, and Ecology Commons, International Public Health Commons, and the Public Health Education and Promotion Commons How does access to this work benefit you? Let us know!

\section{Recommended Citation}

De Rodriguez, Blanca, Ricardo Vernon, and Jorge Solorzano. 2005. "Expanding access to vasectomy services in the Ministry of Health of Guatemala," FRONTIERS Final Report. Washington, DC: Population Council. 


\title{
Expanding Access to Vasectomy Services in the Ministry of Health of Guatemala
}

\author{
Blanca de Rodríguez, APROVIME \\ Ricardo Vernon and Jorge Solórzano, \\ Frontiers in Reproductive Health Program, \\ Population Council
}

November 2005

This study is made possible by the generous support of the American people through the United States Agency for International Development (USAID) under the terms of Cooperative Agreement Number HRN-A-00-98-00012-00 and Subagreement number AI04.05A. The contents are the responsibility of the Population Council and do not necessarily reflect the views of USAID or the United States Government.

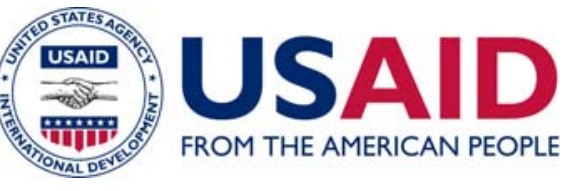

\section{(f) Population Council FRONTIERS}




\section{SUMMARY}

According to the 2002 Maternal-Child Health Survey, 34.4\% of women married or living in consensual unions between 15 and 49 years of age use a modern contraceptive method in Guatemala. Of these, slightly more than one half used female sterilization. Despite the fact that vasectomy is just as effective, is less expensive for the provider and the user and presents fewer risks for the user, less than one percent of women reported using it with their partners. The Ministry of Health of Guatemala $(\mathrm{MOH})$-the main provider of contraceptive methods in the country- delivered their method of choice to $40 \%$ of modern contraceptive users and $30 \%$ of female sterilization users, but to only $1.2 \%$ of vasectomy users. According to their information system, between 2001 and 2003 the MOH performed only 43 vasectomies, despite the fact that in 2001 four surgeons in three hospitals were trained in vasectomy procedures.

The traditional model for introducing vasectomy services consists of sending a doctor to a health unit where a high number of procedures is performed. During their training, they observe operations and perform between five and 10 vasectomies under an instructor's supervision. When they return to their service delivery units they are expected to begin delivering the service unsupervised. However, it has been frequently noted that when they return to their work sites, surgeons do not use their recently acquired skills due to limited demand for the method and a lack of confidence in their skills.

In this project we tested the effectiveness of a systemic model for introducing vasectomy in service delivery units of the $\mathrm{MOH}$, which has four basic components: a) the self-selection of health units according to their response to an invitation to participate in the project; b) the development of a counseling and information model for potential clients; c) training and sensitizing of health teams; and d) on-site training of surgeons.

The first step was to invite 15 hospitals and maternities close to Guatemala City to participate in the project. The requirement for beginning training was identifying at least one man interested in getting a vasectomy and communicating this to the project team. Out of 15 hospitals that were invited, only six complied with this first step and began training. A sensitizing session was held with all personnel, who were instructed on what a vasectomy was. They were also taught to use three materials developed as part of the project to stimulate interest and address potential demand for the method: a poster, a leaflet and a brochure that compared female sterilization with vasectomy and encouraged couples interested in permanent methods to discuss their options and select the method most convenient for them. Following the training session, unit staff members began to work on identifying vasectomy candidates.

Surgeon training was carried out in two stages. The first provided theoretical elements over a half-day period; the second stage comprised supervised practice sessions in their own health units with the vasectomy candidates identified by their health teams.

The health teams identified 205 vasectomy requests in total, and provided the method to 158 men. During the project, eight surgeons from the six participating health units completed their training. On average, surgeons performed 8.25 vasectomies in an average of 3.75 surgery sessions in 12 weeks to complete their training. Follow-up was made with the surgeons an 
average of 22 weeks after their certification. During this period, each surgeon participated in an average of 3.5 surgery sessions and on average performed 9.25 vasectomies. The introduction model therefore showed it was capable of introducing sustainable vasectomy services in the selected sites. An analysis of referral sources showed the importance of having information strategies with multiple communication channels.

The total cost per certified surgeon trained was approximately US \$4,335 or \$2,930 not including the opportunity costs represented by the time used by staff under training. Nearly half of this cost corresponds to the training of health teams in referral health outlets and centers. Of the remainder, about one-third were costs related to post-certification surgeon follow-up. In the short term, the $\mathrm{MOH}$ can replicate the training at an approximate cost of US \$ 900 per certified surgeon, and in the long term, an approximate cost of US \$136 per surgeon.

The profile of vasectomy accepters in Guatemala (and of those that should be offered the method in the future) was men with 2 to 4 children, married or living in a consensual union, Catholic or Evangelical, between 25 and 34 years old, employed, with more than a basic level of schooling, and with the desire to protect their partner's health or whose doctor had recommended a vasectomy. 


\section{EXPANDING ACCESS TO VASECTOMY IN GUATEMALA THROUGH THE MINISTRY OF HEALTH}

\section{INTRODUCTION}

The use of contraceptive methods in Guatemala has rapidly increased in the past few years, from 23.2\% of married women of fertile age (MWFA) in 1987, to 31.9\% in 1995 and $43.3 \%$ in 2002 (34.4\% were users of modern methods). The most frequently used methods in 2002 were female sterilization (16.8\%) and injectables (9\%). Despite the strong demand for permanent methods, the proportion of vasectomy users has always remained below one percent.

Several factors could explain the low use of vasectomy. This method continues to be one of the least known by MWFA, since it is not frequently mentioned in counseling sessions and informative talks given by health service providers to their clients. Access to vasectomy is also more limited than to other methods, since there are few trained surgeons that can deliver the service. Also, the service is nearly always delivered in hospitals and not in outpatient clinics, which means that surgeons often have to vie for the use of an operating room that is often booked with surgeries that are considered to be more important than elected vasectomies.

From a public health perspective, it would be desirable for a greater proportion of couples to prefer vasectomies over female sterilization, since vasectomies have a lower rate of postoperative complications than female sterilization. It is also a less expensive method for the institution that delivers the service, and the client's recovery time is shorter, which reduces their opportunity costs.

According to the National Maternal-Child Health Survey, the Ministry of Public Health and Social Assistance $(\mathrm{MOH})$ was the main source of modern contraceptive methods in Guatemala in 2002, having delivered methods to $32.2 \%$ of users in the country. The $\mathrm{MOH}$ was followed by APROFAM, which delivered methods to $29.4 \%$ of users, the Guatemalan Social Security Institute, or IGSS (11.9\%), and private pharmacies (11.5\%). In terms of permanent methods, the $\mathrm{MOH}$ was the second most important provider that same year for female voluntary surgical contraception (FVSC), delivering the service to $29.8 \%$ of sterilized women, just behind APROFAM (38.1\%). In contrast, the MOH had only delivered the method to $1.2 \%$ of vasectomy users, far behind other providers such as APROFAM (74.4\%), private clinics and hospitals (10.8\%) and the IGSS (7.4\%). Despite the fact that in 2001 four surgeons were trained in clinical vasectomy procedures in three hospitals and clinics in Guatemala City's metropolitan area, the $\mathrm{MOH}$ only performed 12 vasectomies that year, 24 in 2002 and 7 in 2003. In contrast, the number of FVSC in the same years was 2,078, 2,790 and 2,981, respectively. The IGSS was the main provider of vasectomy services in the public sector for many years, with nearly 300 vasectomies per year between 2001 and 2003; however, the service package to which affiliates had a right was modified and in 2004 the IGSS virtually stopped delivering this service. Therefore, in 2004 practically all vasectomy services available in Guatemala were offered by the private sector, especially APROFAM. 


\section{PROBLEM STATEMENT}

In order to increase the use of vasectomy in Guatemala, it is necessary to increase the number of health units that provide effective and sustainable vasectomy services, thus allowing more men access to the method. To introduce vasectomy services in health service delivery units in Guatemala, appropriate service delivery policies and guidelines (already in place in Guatemala), as well as material and equipment are essential; also, surgeons and health teams need to be trained to provide and offer the service, and clients have to be informed of its availability.

The introduction model for vasectomy services in Guatemala has traditionally consisted of sending a doctor to a hospital (frequently outside the country) where a relatively high number of vasectomies are performed. There, the surgeon receives theoretical training and performs between 5 and 6 operations, supervised by an expert. Upon returning to the health unit where they work, surgeons are provided with the equipment and supplies necessary to deliver the service, with the expectation that they will immediately begin to deliver the service routinely. However, since the introduction model has not contemplated promoting the service among potential clients, there is usually low demand for the service and surgeons frequently either do not perform the operation, or only perform a few vasectomies and stop doing so after a short period. Over time, surgeons lose their initial enthusiasm, and due to a lack of practice, they also lose the skills necessary to carry out the procedures safely.

Therefore, the low use of vasectomy in Guatemala is related to the employment of a largely ineffective service introduction model.

\section{SOLUTIONS}

The solution to the problem tested in this project consisted of adapting a systemic model for introducing vasectomy into health units that takes into account the training needs of surgeons and their support staff, as well as the promotion of the service among potential clients. This model was adapted from the one successfully used by the Mexican Social Security Institute (IMSS) (Juarez, 2003) and the experiences gleaned in other operations research projects implemented in Guatemala in recent years.

The model adapted from the IMSS for use in Guatemala has four basic elements: a) the self-selection of health units in line with meeting the established requirements to begin training of their staff; b) the development of a counseling and information model for potential clients; c) training of health teams, and d) on-site training of surgeons.

Section VI describes the model's characteristics in detail as well as the activities implemented for its development. 


\section{OBJECTIVES}

This project's general objective was to develop and test a model for the introduction of noscalpel vasectomy in at least four $\mathrm{MOH}$ hospitals and maternities in Guatemala in order to increase the availability and use of the method $^{1}$.

The specific objectives included:

1. Developing and testing a strategy to train surgeons on site.

2. Developing and testing the effectiveness of an information package to generate requests for vasectomy.

3. Evaluating whether these activities generate sufficient patient volume for at least one of these hospitals or maternities to become a vasectomy training center.

\section{METHODOLOGY}

This was a demonstration project that used a non-experimental design, where interventions were implemented and their effect evaluated in terms of: 1) the feasibility of training surgeons on site; 2) the number of surgeons trained; 3) the number of vasectomies performed; 4) the referral source of vasectomy accepters; and 5) the characteristics of vasectomized clients.

\section{CHARACTERISTISTICS OF THE INTRODUCTION MODEL DEVELOPED AND ACTIVITIES IMPLEMENTED TO TEST IT}

In this project we developed a systemic model to introduce vasectomy into MOH hospitals and maternities in Guatemala. This model has four basic elements: a) self-selection of health units according to their implementation of activities established as a requirement to begin training; b) development of a counseling and information model for potential clients; c) training of health teams, and d) on-site training of surgeons. This chapter explains the characteristics of these elements and the activities implemented to test the introduction model.

\subsection{Selection of Service Delivery Units}

Health systems frequently spend considerable resources on training personnel that do not have a real interest in project activities or a motivation to implement them. In the case of organizations with weak supervision systems and limited administrative capacity to ensure that service providers comply with the guidelines and activities planned, training

\footnotetext{
${ }^{1}$ The study's original protocol proposed including at least two IGSS clinics or hospitals and two MOH hospitals. However, when this project began, the new IGSS authorities redefined the family planning package to which affiliates and beneficiaries have a right, and the IGSS virtually stopped providing vasectomy services. Faced with this situation, we decided to implement all these activities in the MOH.
} 
unmotivated staff can simply become a waste of resources, since the skills obtained from training are not put into practice. To avoid this, we established the following requirement for beginning the project's training: hospital clients interested in having a vasectomy had to be identified. Hospitals that could not comply with this requirement effectively withdrew from further participation in the project.

At the outset, we selected 15 hospitals and maternities near Guatemala City with the largest volume of prenatal visits, deliveries and female sterilizations in 2003 and $2004^{2}$. This was done to ensure that the selected hospitals covered a population large enough to ensure a minimum demand for the service, and that training could therefore be cost-effective.

During a second stage, project personnel visited each of these hospitals and explained the project characteristics to the hospital director and the health team, as well as the activities that would have to be implemented. In this meeting, health teams were invited to participate in the project, and they were informed that training activities could begin once they had identified at least one man interested in having a vasectomy and had informed the project coordinator of this. One of the hospitals was eliminated on this first visit, since its staff were not willing to absorb project activities if new personnel were not incorporated. A second hospital also decided not to participate since they did not have the supplies necessary -such as gloves and anesthetics- to deliver the service, and they were also in a process of staff restructuring that would complicate the introduction of new services.

The directors from the remaining 13 hospitals stated their interest in participating in the project and their agreement with the project requirements. However, only the directors of the facilities in Amatitlán, Chimaltenango, Cuilapa, Progreso, and Zones 18 and 19 of Guatemala later contacted the project coordinator to inform her they had identified at least one vasectomy candidate and were ready to start training activities. Thus, from the first list of 15 hospitals, over half withdrew from the study and only six remained.

\subsection{Development of an Information Model for Potential Clients}

Vasectomy is a relatively little known service in Guatemala. For this reason, the model had to have a component to promote the service, which the MOH could sustain and would allow potential clients to be informed of the service's availability. To develop the user information component we took into account the results of studies (see, for example, Vernon, 1996) that have shown that vasectomy accepters in Latin America are typically men that are between 30 and 40 years old, are married or in a consensual union, live in large cities, have a stable job, have a higher-than-average level of education and relatively small families, and have been users of different temporary methods, to a large degree those that require the participation of males, and are tired of doing so. These studies have also shown that vasectomy accepters receive information from different channels throughout all the stages in the process of deciding whether to have the operation. In the first stage, men

\footnotetext{
${ }^{2}$ The units preselected and visited between July 2004 and May 2005 were the hospitals in Amatitlán, Chimaltenango, Coatepeque, Cuilapa, Huehuetenango, Malacatán, El Progreso, Quetzaltenango, San Marcos, Santa Cruz del Quiché, Sacatepequez, Suchitepéquez, Zacapa and the maternities in Zones 18 and 19 of Guatemala City.
} 
find out about vasectomies through multiple sources, especially their wives, health service providers, mass media and friends and relatives. In the second stage, men seek more information by speaking with friends and men who have already had a vasectomy, reading leaflets and other materials and consulting health service providers. At a third stage, the man makes the decision after speaking with his partner and comparing vasectomy and female sterilization as options. Most men report that their partner was the most influential person in their decision-making process.

Since the MOH does not have a budget for mass media advertising, vasectomy would have to be promoted mainly among MOH hospital and clinic users, especially among women who had just delivered a baby, who requested female sterilization, and men and women that attended the hospital for any other reason and fit the profile of vasectomy accepters. Also, we thought that vasectomy accepters from the project could be very effective promoters of the method and decided to invite them to collaborate, providing information and material to their friends and relatives.

In order to implement the promotion system, a half-day meeting was held at each participating hospital and several nearby health centers. In order to support information activities we developed three promotional materials that emphasized the characteristics of the methods which clients felt were the most important when making a decision. The following materials were developed:

- The “Family Planning is Also Men’s Business (La planificación familiar también es cosa de hombres)" leaflet is half-letter size, describes the operation's four characteristics and suggests that the reader request more information at the clinic or hospital. The leaflet was designed to be handed out to men in hospital waiting rooms and communities. On average, 5,000 copies were provided to each participating site (2,000 to the hospital and 3,000 to the referral centers). The leaflet is presented in Appendix 1.

- The “Family Planning is Also Men’s Business (La planificación familiar también es cosa de hombres)" poster is double letter size, has the same information as the leaflet plus two additional characteristics. The poster was designed to be placed in public waiting rooms in hospitals and clinics and inform attendees of the availability of the method. On average 20 posters were given to each hospital and five to each referral health center. The poster is presented in Appendix 2.

- The “Let's Decide as a Couple (Decidamos en Pareja)” brochure, printed in color on a letter-size page, has information on vasectomy and female sterilization. The brochure recommends that couples that want to use a permanent method read it together and go to the health unit to obtain more information on these methods. The brochure was handed out to women that showed an interest in permanent methods during the postpartum and waiting room talks, or during family planning counseling sessions. Each hospital received 2,000 brochures on average and 1,000 were given to nearby health centers. Appendix 3 shows the brochure. 
- The project also paid for two large cloth displays along the street at each participating hospital so that the people that walked by would know the method was available at that health unit.

Other materials produced by the MOH and the Calidad de Salud bilateral project were also distributed. These included brochures on all methods, on vasectomy and on female sterilization, a flip-chart on family planning methods, algorithms and cards for the use of the balanced counseling strategy in family planning, a video on vasectomy and the $\mathrm{MOH}$ family planning service delivery guidelines.

\subsection{Training of Health Teams}

In contrast to the vasectomy introduction model used previously in Guatemala, where only the surgeon was trained, we included a training component to engage all personnel from the participant hospital and nearby health centers that could serve as referral centers for patients. The expectation was that in this way everyone would cooperate in informing users and identifying potential clients.

In total, six workshops were held in hospitals where the vasectomy service was introduced, two in clinics in the periphery, 14 in health centers and eight in health outlets near participating hospitals. Workshop participants included 105 doctors, 91 professional nurses, 386 nurse auxiliaries, 20 social workers and 122 other employees, such as statisticians, secretaries and doormen.

The workshops lasted four hours. The topics covered included an explanation of the project and of no-scalpel vasectomy, the importance of counseling on all available methods, what information strategies to use and how to use the promotional materials, how to refer patients, how to register the data to evaluate interventions and how to obtain clients' informed consent. Also, an action plan was drafted in each unit for the subsequent months.

A questionnaire was applied before and after the workshops to collect information on the characteristics of participants and evaluate changes in their knowledge. Results showed that 12 percent of participants had already seen a vasectomy and that $11 \%$ had referred clients for vasectomy. Seventy-five percent had taken a family planning course, $70 \%$ of them in the past two years. Only $11 \%$ said they always mention vasectomy to their female family planning patients and even fewer (7\%) mentioned it to their male patients. In terms of basic knowledge on vasectomy, the average score increased between the pre-test and the post-test from 82 to 95 points out of a possible 100. One of the least known items in the pre-test was that during the first three months or before the first 20 ejaculations after a vasectomy a man continues to be fertile. In the workshop we recommended that participants target their messages to men with the typical profile of vasectomy accepters. However, they still had many doubts by the end of the workshop about what this profile was. For example, only $13 \%$ considered that having a higher level of education and $42 \%$ that having a stable conjugal relationship were significant characteristics for identifying potential vasectomy clients. 
IEC activities in the units were initiated immediately after the training workshops. In total, participating units reported giving 1,575 talks to groups where at least one mention was made of vasectomy. They also provided 2,191 counseling sessions (including 376 to couples) and distributed 7,169 comparative brochures, almost half of them in participating hospitals. In addition, units reported having handed out 10,659 leaflets and displayed on average three posters each month.

During the first months of the project, referral hospitals and clinics kept a record of patients and identified the ones that had been given information on vasectomy. According to these records, nearly $22 \%$ of those attending an outpatient clinic and participating health centers received some information on vasectomy during their visit. However, an analysis of these records showed that recommendations for targeting men that fit the profile of vasectomy accepters were not followed. For example, $28 \%$ of those without children received information, but less than $17 \%$ of those that had between 1 and 3 children did; only $45 \%$ of those between 30 and 39 years of age received information; there were practically no differences in the proportions that received information when comparing those with a partner and those without one; information was given to a much larger proportion of men with no education than men that had completed elementary school or more.

Remarkably, 54\% of the project's vasectomy accepters agreed to become voluntary promoters. About $42 \%$ said they were willing to have men who were interested in vasectomy call them on the phone to give them information. Twenty-five percent said they were willing to attend one training session and $20 \%$ preferred to have only leaflets and brochures given to them to hand out to friends. There are no data on the degree to which promotional activities were carried out, except for the number of persons that said they had been referred by another vasectomized man.

\subsection{Surgeon Training}

Surgeon training was conducted in two stages: theoretical training and practical training.

\section{Theoretical Training}

Theoretical training lasted for half a day and was done both in group and during individual sessions. In it, project characteristics were explained, as well as the no-scalpel technique, promotion strategies that their team had to implement, and how to fill out the research project's records. Also, attendees watched a video on the no-scalpel vasectomy technique.

The first theoretical training session was held in November 2004 in Guatemala City. Twelve doctors attended; they came from hospitals in Amatitlán (2), Chimaltenango (2), Antigua, Cuilapa (2), Zone 18 (3), Zone 19 hospitals and the Zone 19 clinic. Later, theoretical training was provided in January 2005 to a doctor in Chimaltenango, in March and August 2005 to two doctors from Cuilapa, in May 2005 to two doctors from the Amatitlán maternity and one from Progreso, and in June to one doctor from Progreso. All later training was provided individually up to November 2005. 
The pre-test and post-test for the training included items which determined the knowledge of surgeons on $\mathrm{MOH}$ norms, existing vasectomy techniques, postoperative precautions, recommendations that must be given to the client before and after the procedure and questions about the most frequent rumors, such as whether vasectomy affects sexual desire in men. The average grade in the pre-test was 69 points and in the post-test 80 points. In the pre-test, seven out of 12 doctors knew that the $\mathrm{MOH}$ norms required they obtain the patient's informed consent due to the procedure's irreversibility; half knew vasectomy's mechanism of action, and they all knew that vasectomy does not provide protection against HIV/AIDS. The greatest increase in knowledge between the pre and post-test had to do with knowledge of the precautions before the procedure: before training, only 5 answered correctly, as opposed to all 12 doctors after the course.

\section{Practical Training}

Practical training consisted of performing several vasectomies under a trainer's supervision. This training was carried out in the trainee's service delivery site with clients whose interest in vasectomy had been identified by their own health teams. The trainer would usually do the first vasectomy (or coordinate doing a vasectomy, where the trainer would pull out and excise the first vas deferens and allow the trainee to do the same with the second vas deferens). The following vasectomies were performed by the trainee under the supervisor's observation; the supervisor would only intervene in case the trainee could not carry out a particular step. The supervisor used a checklist to observe whether trainees were following the different steps established by the protocol for care. The checklist used by trainers is presented in Appendix 4. Supervised practices continued until two requirements were fulfilled: the trainer determined the trainee had the skills and knowledge necessary to do the operations alone; and the trainee said he or she felt the necessary confidence to do the procedures without supervision.

Of 19 doctors that took theoretical training, only 14 began practical training, that is, they performed at least one supervised vasectomy. The other five doctors did not continue for different reasons. The Antigua participant did not agree to continue in the project; the Chimaltenango director assigned another participant; in the Zone 19 periphery clinic it was decided that the project should be implemented in the maternity, and the two Cuilapa participants simply did not show up, and another doctor showed up on the day the trainer began practical training.

Of the 14 doctors that began practical training, to date eight doctors have been certified and four were still in the process of training, under the supervision of the Zone 18 and Zone 19 surgeons. The two Cuilapa doctors decided not to continue, preferring instead that other doctors be trained.

A revision of the checklists employed by the supervisor in the training period shows that during the first three vasectomies, 58\% of surgeons competently performed all the steps prior to the procedure: checking biographical information, determining whether the clients had made a definite decision, repeating pertinent information on informed consent, and the physical examination necessary to eliminate precautions. This improved to $78 \%$ in the fourth supervised operation. The most difficult steps in the surgical technique ranged from 
finding the vas deference percutaneously to the ligation of the contralateral vas deferens; $40 \%$ of surgeons did this competently in the first two surgeries and $58 \%$ in the third practice surgery. According to the supervisor's opinion, most surgeons need between six and seven supervised vasectomies to perform these procedures competently and to acquire the confidence to do them without supervision, although there was one student that requested the instructor's presence in twenty vasectomies.

\section{RESULTS}

\subsection{Training of Surgeons and Establishment of Training Centers}

One of the project's objectives was to assess whether the on-site surgeon training strategy could be feasibly implemented. The aim was to train at least four surgeons and leave four working vasectomy service centers. Another objective was to see whether at least one of these could become a surgical training center.

Table 1 shows the project's achievements. A total of 158 vasectomies were performed in 54 sessions, with an average of 2.93 vasectomies per session. Eight surgeons were certified to continue to offer the service without supervision and four more surgeons were continuing their training until September 2005, when this report was completed.

Table 1

Average number of no-scalpel vasectomies by place and number of sessions

\begin{tabular}{|l|r|r|r|r|r|}
\hline \multicolumn{1}{|c|}{ Place } & \multicolumn{1}{c|}{$\begin{array}{c}\text { No. of } \\
\text { sessions }\end{array}$} & $\begin{array}{c}\text { No. } \\
\text { Vasectomies }\end{array}$ & $\begin{array}{c}\text { Average per } \\
\text { session }\end{array}$ & \multicolumn{2}{c|}{ Surgeons } \\
\hline & & & & Certified & In process \\
\hline Amatitlan & 12 & 31 & 2.58 & 2 & 2 \\
\hline Chimaltenango & 7 & 17 & 2.43 & 2 & 0 \\
\hline Zone 18 & 12 & 31 & 2.58 & 3 & 0 \\
\hline Zone 19 & 19 & 71 & 3.74 & 0 & 0 \\
\hline Cuilapa & 1 & 3 & 3.00 & & 0 \\
\hline Progreso- & 3 & 5 & 1.67 & 0 & 1 \\
Guastatoya & $\mathbf{5 4}$ & $\mathbf{1 5 8}$ & 2.93 & $\mathbf{8}$ & $\mathbf{4}$ \\
\hline Total & & & & & 0 \\
\hline
\end{tabular}

Table 2 provides data on the vasectomy introduction model, especially the on-site training of the eight surgeons certified. Of these, three were general surgeons and five were ObGyns. The training lasted an average of 12 weeks, i.e., from the first training session to the session when the trainer determined that the trainees had reached the required technical competence and the trainees said they felt confident in their skills to deliver the service without supervision. As can be noted, this average is skewed by one surgeon that required 24 weeks to be certified. Without counting this case, the other seven surgeons were certified on average in 10.5 weeks. On average, the surgeons required a total of 3.75 operating sessions and 8.25 vasectomies to be certified. Again, these averages are influenced by the numbers represented by the surgeon from the Zone 19 maternity, who 
took 7 sessions and 22 operations to be certified. In contrast, the other 7 surgeons required 6.25 surgeries in 3.28 sessions to be certified.

Table 2

Number of no-scalpel vasectomies per hospital, surgeon, certification time and sessions before and after certification*.

\begin{tabular}{|c|c|c|c|c|c|c|c|}
\hline $\begin{array}{l}\text { Doctor and } \\
\text { Service }\end{array}$ & Prof. & $\begin{array}{c}\text { Weeks lapsed } \\
\text { between first } \\
\text { practice } \\
\text { session and } \\
\text { certification } \\
\text { week }\end{array}$ & $\begin{array}{l}\text { Number of } \\
\text { sessions }\end{array}$ & $\begin{array}{c}\text { No. } \\
\begin{array}{c}\text { Vasectomies } \\
\text { until }\end{array} \\
\text { certification }\end{array}$ & $\begin{array}{l}\text { Weeks from } \\
\text { certication up } \\
\text { to September } \\
2005\end{array}$ & $\begin{array}{c}\begin{array}{c}\text { Sessions } \\
\text { from }\end{array} \\
\text { certification } \\
\text { to } \\
\text { September } \\
2005 \\
\end{array}$ & $\begin{array}{c}\text { Post- } \\
\text { certification } \\
\text { vasectomies }\end{array}$ \\
\hline \multicolumn{8}{|l|}{ Amatitlan } \\
\hline 1 & Surgeon & 9 & 3 & 8 & 24 & 4 & 4 \\
\hline 2 & Surgeon & 9 & 5 & 9 & 24 & 3 & 6 \\
\hline \multicolumn{8}{|l|}{ Chimaltenango } \\
\hline 3 & Surgeon & 9 & 2 & 7 & 20 & 3 & 3 \\
\hline 4 & Ob/Gyn & 9 & 3 & 4 & 32 & 3 & 4 \\
\hline \multicolumn{8}{|l|}{ Zone 18} \\
\hline 5 & Ob/Gyn & 13 & 3 & 6 & 26 & 3 & 5 \\
\hline 6 & Ob/Gyn & 11 & 4 & 4 & 19 & 4 & 5 \\
\hline 7 & Ob/Gyn & 13 & 3 & 6 & 15 & 4 & 5 \\
\hline \multicolumn{8}{|l|}{ Zone 19} \\
\hline 8 & Ob/Gyn & 24 & 7 & 22 & 19 & 4 & 42 \\
\hline Total & & 97 & 30 & 66 & 179 & 28 & 74 \\
\hline Average & & 12.12 & 3.75 & 8.25 & 22.37 & 3.5 & 9.25 \\
\hline
\end{tabular}

* Only includes procedures carried out by certified doctors. Does not include 12 vasectomies performed by the trainer or vasectomies performed by doctors that were continuing with training.

Table 2 also shows that the training model employed was effective in establishing sustainable services. The four hospitals and maternities continued to deliver the service after the certification of their surgeons. In total, these centers have carried out 28 postcertification surgery sessions with a total of 74 vasectomies, that is, more than two vasectomies per session. The productivity of the surgeon that required more of the supervisor's attention during the training stage should be noted. This surgeon participated in four sessions after certification and performed 42 vasectomies, an average of 10.5 vasectomies per session. In contrast, the other surgeons performed 32 surgeries in total during 24 sessions, an average of 1.33 vasectomies per session. All centers have had at least one monthly session after surgeon certification.

Table 2 also shows that the maternities where surgeons were certified in zones 18 and 19 of Guatemala City can function as vasectomy training centers. The most productive unit has been the Zone 19 maternity, which after certification has had four sessions with an average of 10 surgeries per session. The maternity in Zone 18 has performed 15 vasectomies in four sessions, i.e., slightly over three vasectomies per session. These numbers will probably allow a surgeon in training to be certified in one or two sessions and two surgeons in two to three sessions. The Amatitlán and Chimaltenango hospitals have performed an average of two vasectomies per session, which will also allow for the training of surgeons in a larger 
number of sessions; this appears feasible if the trainees work in the same cities where the hospitals are located. It should be noted that we recommend these centers be used complementarily to speed up surgeon training processes, but not to completely substitute on-the-job training, which is an essential component of the introduction model.

After finalizing the training sessions where 69 supervised vasectomies were performed, the supervisor and surgeons answered a questionnaire to obtain suggestions on how to improve the training methodology. In the trainer's view, the most important steps for reinforcing trainee mastering of the technique were: the manual ability to locate and block the vas deferens percutaneously, to locate and excise the vas deferens with $\mathrm{Li}$ forceps and, the most difficult one to execute, to isolate and excise the second vas by means of a single incision at the scrotal raphe. With regard to the trainee's technical skills, on a scale from 0 a 10 points, $17.4 \%$ of trainees obtained between 2 and 5 points, 31.9\% from 6 to 7 points and $49.3 \%$ from 8 to 9 points. Only one of the surgeons (1.4\%) got 10 points. The most common suggestion to improve training and develop surgeons' skills more rapidly was to perform a greater number of supervised operations.

Trainees said the steps in the technique which they found most difficult were isolating the first vas deferens and delivering the second vas deferens to the incision made in the scrotum. Perhaps this could be learned more rapidly if surgeons practiced locating the vas deferens on an anatomical model, on their own bodies, on peers that were also being trained, or on patients in the urology ward in their hospitals before beginning their training in vasectomy. The delivery of the second vas deferens could be simulated using an ink marker as the target incision.

\section{Complications}

Table 3 shows the characteristics of the five complications observed during project development. Two of the complications were seen at the maternity in Zone 19, and one in each one of the Cuilapa, Chimaltenango and Amatitlán hospitals. Of the five complications, two showed up post operatively and three after hospital discharge. 
Table 3

Description of complications by place where procedure was performed

\begin{tabular}{|l|c|c|c|c|c|}
\hline Place & \multicolumn{5}{|c|}{ Description } \\
\hline & $\begin{array}{c}\text { Slight } \\
\text { edema on } \\
\text { right } \\
\text { testicle }\end{array}$ & $\begin{array}{c}\text { Slight edema } \\
\text { on left testicle }\end{array}$ & $\begin{array}{c}\text { Hematoma } \\
48 \text { hours } \\
\text { post } \\
\text { operation }\end{array}$ & $\begin{array}{c}\text { Vago-vagal } \\
\text { reflex }\end{array}$ & Total \\
\hline Cuilapa National Hospital & 1 & 0 & 0 & 0 & 1 \\
\hline $\begin{array}{l}\text { Chimaltenango National } \\
\text { Hospital }\end{array}$ & 0 & 0 & 0 & 1 & 1 \\
\hline Amatitlan Maternity & 0 & 0 & 1 & 0 & 1 \\
\hline Zone 19 Maternity & 0 & 1 & 0 & 1 & 2 \\
\hline Total & 1 & 1 & 1 & 2 & 5 \\
\hline
\end{tabular}

Patients that experienced complications during the surgical procedure were satisfactorily discharged from the hospital and received a check-up eight days afterwards. Also, patients that asked for a consultation due to complications after discharge were found to have no problems in the subsequent check-up. All trans-operative complications were solved appropriately by the supervising doctor and the post operative ones by the corresponding unit doctors.

\section{Training on Spermogram Follow-Up}

In each participant hospital we trained one person from the laboratory to perform follow-up spermograms. All patients were given an appointment after 8 days for a postoperative check-up, and after three months (with their sperm sample) to verify the intervention's success. Few patients returned after three months for their check-up. The importance of verifying the operation's success by means of the laboratory follow-up should be emphasized, and as well as ensuring that the patient understood the instructions given to him after the operation in order to avoid subsequent problems.

\subsection{Effectiveness of Promotion Strategies}

The project's second objective was to test promotional strategies that generate demand for vasectomy in sufficient quantities to train surgeons and maintain their skills. The strategies tested succeeded in generating 205 vasectomy requests and lead to 158 vasectomies. This quantity was sufficient to train surgeons and preserve their skills after certification.

In order to evaluate the effectiveness of the different promotional strategies, we asked vasectomy accepters about their information sources and the sources that had the greatest influence on their decision. In all cases more than one answer was accepted, and therefore the sum of percentages is generally over $100 \%$. Wives or partners were the most consulted sources and also the most influential: 68\% of men said they had spoken with their partner during the decision-making process and $41 \%$ said she had been the person who had had the most influence on their decision to get a vasectomy. Doctors, nurses and social workers were the source of information for $31 \%$ and the most influential source for $9 \%$. Friends and 
relatives as well as other vasectomized men were a source of information for more than $21 \%$ of men and the most influential source for $6 \%$. Promoters were a source of information for $6 \%$ and the most influential source for $3 \%$ of men. Nearly half of the men (46\%) said they had made the decision on their own without anyone having a predominant influence on them. Despite the fact that vasectomized men were identified by $6 \%$ as the most important influence in their decision-making, 81\% said they knew at least one man who had had a vasectomy. When asked if they had spoken to their partner about which method was more convenient -whether vasectomy or female sterilization-, $92 \%$ of men answered that they had.

Fifty-three percent also said they had received information from the project's brochure and poster, 42\% through newspapers and magazines, and between 4 and $8 \%$ from radio or television.

We also asked what had been the referral source for them to select the specific hospital where they had the operation. Twenty-nine percent said their wives; 38\% mentioned personnel from the same hospital, 25\% personnel from other health centers, $18 \%$ friends or relatives, and slightly less than $10 \%$ radio or $\mathrm{TV}$, the health promoter, poster, leaflet or another vasectomized man.

Therefore, data indicate that the effectiveness of the intervention depended more on the multiplicity of channels and sources than on any one of them in particular. Certainly, providing information on vasectomy to women immediately postpartum and giving them material to look over with their husbands appears to be very effective. Giving leaflets and brochures to vasectomized men so they in turn give them to their friends is a strategy that requires minimal effort and has certain degree of effectiveness, as does distributing material in the waiting rooms. Perhaps the most difficult intervention was the training of personnel in nearby health centers to serve as a referral source for patients. However, $25 \%$ of patients seem to have come from there, so this strategy should only be eliminated in the absence of resources.

The maternity in Zone 19 of Guatemala was the most successful unit in generating patients. In interviews with the maternity director and surgeon, as well as with the nursing auxiliary in charge of promotion, the success of the strategy was attributed to family planning talks they gave daily to women who had just delivered a baby. In these talks they provided information on vasectomy and gave them the comparative brochure to talk over with their partners. Also, they felt that the involvement of the entire unit's personnel had been significant, since even the doorman sometimes provided information to persons who were reticent about requesting information from counselors in a more formal manner. They also considered the distribution of materials and talks with men in the waiting areas as well as the referrals from satisfied clients to be significant components in their success.

With regard to other conditions that favored the acceptance of vasectomy, health providers highlighted the importance of operating on Friday after 11:00 a.m., in order to make it easier for the men to rest on the weekend and so they would not have to ask for more than half a day off work. 


\subsection{Profile of Vasectomized Men}

Reviewing the characteristics of vasectomy accepters is important since it provides the profile of men who might need information on the method and the information strategies that must be employed.

Ninety six percent of clients resided in areas covered by the hospitals and maternities where they had their operation; only four percent lived in a nearby town or neighborhood. This reinforces the idea that promotion within the health units is what allows for the identification of potential vasectomy clients.

Table 4 presents a summary of the principal characteristics of the 158 clients given a vasectomy that requested it throughout the project. It can be seen that all men were married or living in consensual unions, and that $58 \%$ of patients were between 25 and 34 years old. Also $15 \%$ were between 35 and 39 years of age and $11 \%$ between 40 and 44 . The men had a level of schooling higher than the average in the country, as $46 \%$ had 10 or more years of schooling (diversified or university) and 23\% had secondary schooling (between 7 and 9 years of schooling).

More than half the patients were Catholic and $42.4 \%$ were Evangelical. More than twothirds of patients were from the Ladino or Spanish-speaking ethnic group. Since the project was carried out in large urban areas or near the capital city, it is surprising that one-third of the clients were indigenous, which shows an unanticipated level of acceptance among clients belonging to that ethnic group.

With regard to the number of children, more than $65 \%$ had two or three, and more than $20 \%$ had four children. There were practically no clients with one child or less, and a small proportion of clients had five or more children, including a man with 12 children. Most patients (56\%) had the operation when their youngest child was less than one year old, which shows the importance of offering the service through women in the postpartum period, and almost $40 \%$ had a child between one and five years of age. Out of six cases where the youngest child was more than five years old, the child only had one sibling in one case, and in five cases the child had five or more siblings. Table 4 shows that most patients had a stable job which allowed them to be classified as urban lower-middle class. 


\section{Table 4}

Characteristics of the 158 clients that had a vasectomy during the project

\begin{tabular}{|c|c|c|}
\hline VARIABLE & NUMBER & PERCENTAGE \\
\hline \multicolumn{3}{|l|}{ AGE } \\
\hline 20 to 24 years & 13 & 8.2 \\
\hline 25 to 29 years & 43 & 27.2 \\
\hline 30 to 34 years & 49 & 31.0 \\
\hline 35 to 39 years & 24 & 15.2 \\
\hline 40 to 44 years & 18 & 11.4 \\
\hline 45 to 49 years & 9 & 5.7 \\
\hline 50 to 54 years & 2 & 1.3 \\
\hline \multicolumn{3}{|l|}{ EDUCATIONAL LEVEL } \\
\hline None & 3 & 1.9 \\
\hline Primary & 45 & 28.5 \\
\hline Secondary & 37 & 23.4 \\
\hline Highschool & 52 & 32.9 \\
\hline University & 21 & 14.4 \\
\hline \multicolumn{3}{|l|}{ RELIGIÓN } \\
\hline Catholic & 80 & 50.6 \\
\hline Evangelical & 67 & 42.4 \\
\hline Mormon & 4 & 2.5 \\
\hline Jehova's Witness & 3 & 1.9 \\
\hline None & 4 & 2.5 \\
\hline \multicolumn{3}{|l|}{ ETHNICITY } \\
\hline Ladino (Spanish speaking) & 111 & 70.3 \\
\hline Indigenous & 47 & 29.7 \\
\hline \multicolumn{3}{|l|}{ MARITAL STATUS } \\
\hline Married & 128 & 81.0 \\
\hline Consensual Union & 30 & 19.0 \\
\hline \multicolumn{3}{|l|}{ NUMBER OF CHILDREN } \\
\hline $0-1$ children & 2 & 1.3 \\
\hline 2 children & 51 & 32.3 \\
\hline 3 children & 52 & 32.9 \\
\hline 4 children & 32 & 20.3 \\
\hline 5 or more children & 21 & 13.3 \\
\hline \multicolumn{3}{|l|}{ AGE OF THE YOUNGEST CHILD } \\
\hline Younger than 1 month & 4 & 2.5 \\
\hline 1 to 11 months & 85 & 53.8 \\
\hline 1 to 5 years & 63 & 39.9 \\
\hline Over 5 years & 6 & 3.8 \\
\hline \multicolumn{3}{|l|}{ TYPE OF EMPLOYMENT } \\
\hline Commerce & 32 & 20.3 \\
\hline Small factory owners & 23 & 14.6 \\
\hline Management & 23 & 14.6 \\
\hline Factory work and other machine operators & 23 & 14.6 \\
\hline Drivers & 18 & 11.4 \\
\hline Craftsmen & 15 & 9.5 \\
\hline Other employment & 15 & 9.5 \\
\hline Unemployed & 5 & 3.2 \\
\hline Teachers & 4 & 2.5 \\
\hline TOTAL & 158 & 100.0 \\
\hline
\end{tabular}

According to these data, then, in Guatemala, the profile of the man interested in a vasectomy is one with two to four children, married or in a consensual union, Catholic or 
Evangelical, between 25 and 34 years of age, employed, with a level of schooling higher than elementary, and who wishes to protect the health of his wife or partner or has been recommended for a vasectomy by the doctor.

\subsection{Decision-Making Process}

As well as identifying the referral sources and the profile of men that decided to get a vasectomy, we examined men's decision-making processes for requesting a vasectomy.

We asked all men how long it took them from first hearing about vasectomy until they decided to get an operation. Over 56\% said they had made the decision in less than two months and $13 \%$ said it had taken them about two months. Fourteen percent said it had taken them between three and six months. Therefore, more than two-thirds of men decided to get the operation in less than three months after knowing about its availability, and only $14 \%$ said they had decided to get the operation 12 or more months after learning of the existence of the method.

We also asked them if they had discussed with their partner which method was more convenient, whether vasectomy or female sterilization, and 92\% said they had.

We also asked them about the reasons that led them to decide on a vasectomy. Sixty-five percent said it was to protect their partner's health or because they had been referrred by their doctor to have one. A significant proportion mentioned some advantage of vasectomy over female sterilization, such as its greater safety (16.4\%), greater effectiveness (9.5\%), and the fact that hospitalization is not necessary and recovery from the operation is faster (17.7\%); another $18.9 \%$ mentioned that they did not want to have more children or their wife's refusal for female sterilization. Only slightly more than one percent mentioned economic reasons.

The information provided by the project's promotional materials therefore seems to be very closely linked to the characteristics in which the men that chose the method were most interested.

\subsection{Cost Analysis}

Table 5 presents the costs incurred by APROVIME to implement the introduction model for vasectomy, as well as the implicit costs for the $\mathrm{MOH}$, using as a point of reference their salary levels, perdiem and travel expenses.

During the project, eight surgeons were certified and four more were nearly halfway through the certification process. For this reason, in order to calculate cost efficiency we considered a total number of 10 trained surgeons. All costs are in U.S. dollars.

The total cost of the project, including the MOH personnel's opportunity costs, was US $\$ 43,355$, that is to say, approximately $\$ 4,335$ dollars per trained surgeon or $\$ 274$ per surgery performed. If we do not include the costs of personnel still being trained (but including the time of coordinators, instructors and supervisors), the total cost would be 
$\$ 29,301$, in other words, $\$ 2,930$ per trained surgeon and $\$ 185$ per vasectomy performed. If we take into account the MOH's salary structure and the per-diem and travel expense scale, the total cost of the project would be $\$ 29,204$ and $\$ 17,571$ without taking into account the time of personnel still being trained.

The most expensive component of the project was the training of health teams. Training personnel in 30 health units cost nearly $\$ 20,000$, almost half the cost of the project. If only the teams from the six units that directly delivered vasectomy services were trained, then the training costs for teams would be reduced by approximately $80 \%$. In future exercises, we recommend that the training of health teams in nearby health centers and outlets be eliminated, or that only one representative from each health district be invited to the training session and be handed the materials in order to replicate it at the monthly district meetings.

The theoretical and practical training of surgeons was relatively inexpensive. Without taking into account coordination visits, the costs for these training sessions were near $\$ 8,000$, that is to say, around $\$ 800$ per trained surgeon. If we take into account the postcertification follow-up costs, then the costs are almost twice as high, in other words, $\$ 1,600$ dollars per trained surgeon (or nearly $\$ 660$, taking into account the MOH salary levels). The costs for promotion and information to users represented close to $\$ 400$ per participant center, including the time used by nurses, as well as the design and reproduction of the materials used (leaflet, poster and comparative brochure).

If the $\mathrm{MOH}$ were to replicate the introduction strategy employed by the project, costs would be reduced considerably, since the salary structure and per-diem and travel expenses are much lower than the ones used by APROVIME. Also, the replication could be made without expenses related to the development of materials and with fewer coordination visits. We believe the MOH could replicate training at an approximate cost of US \$ 900 per surgeon, including post-certification follow-up costs and promotion costs, but decreasing the costs related to training health teams in nearby health centers and outlets and not taking into account the opportunity cost represented by trainees' time. We also believe that these costs would decrease over time as the number of trained surgeons increases and the method's popularity rises. As a reference point for the minimum cost in the long term, we considered that a practical training procedure could be done with US $\$ 16.45$. Considering we need 8.25 supervised vasectomies on average, the total cost would be about US $\$ 136$, taking into account the $\mathrm{MOH}$ salary structure, the use of 20 minutes of the instructor's and the trainee's time per procedure, the time of assisting personnel and the cost of materials used to perform the vasectomy. 


\section{Table 5}

Introduction Model: Actual costs of the APROVIME project and MOH implicit costs, by area, in US dollars

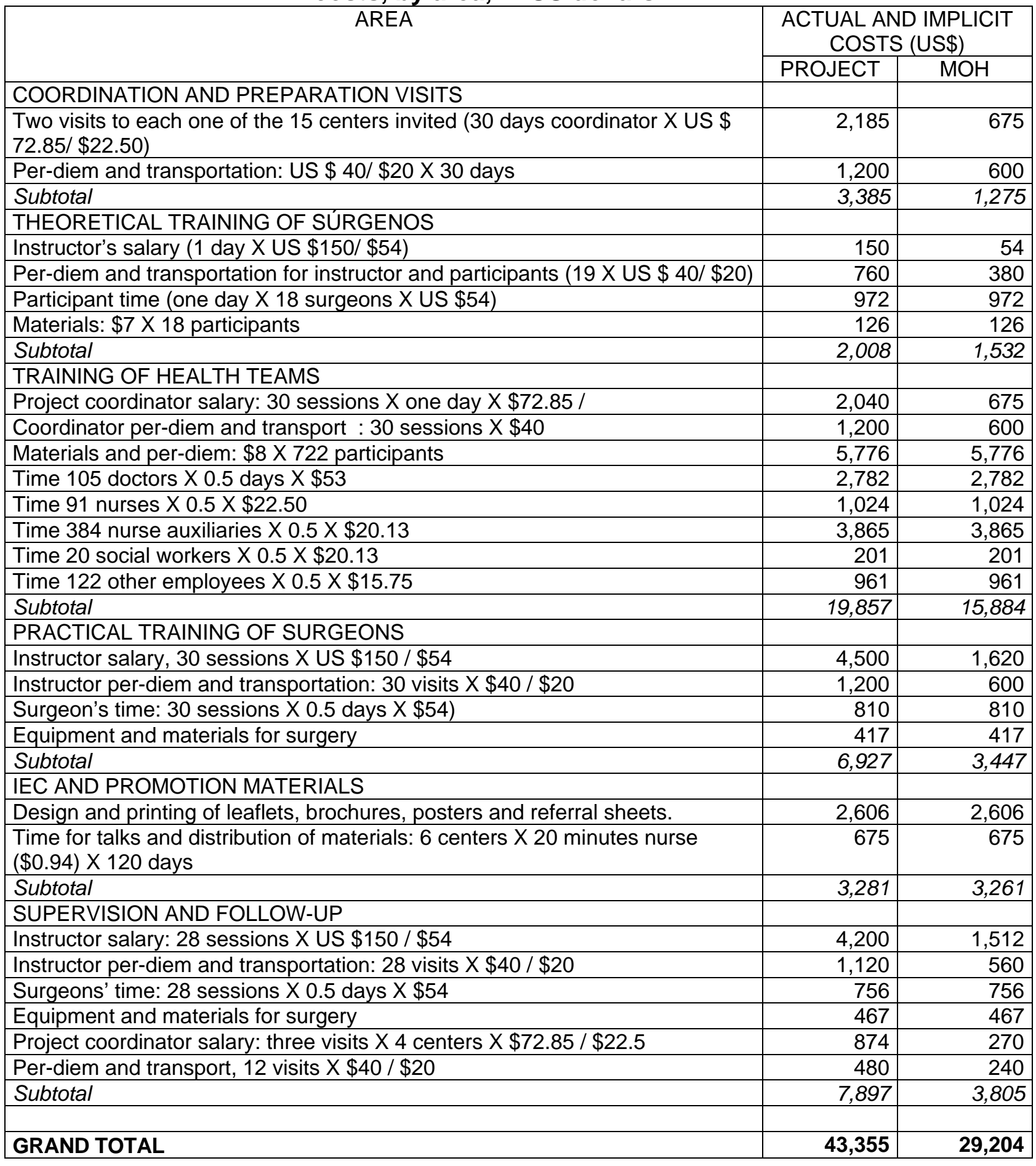




\section{DISSEMINATION AND UTILIZATION OF RESULTS}

Results were presented to mid-level personnel, directors and operations personnel from each participating center in a half-day workshop on July 15, 2005. Other reproductive health service providers that could use these strategies were also invited to this workshop, as well as donors that could finance replication activities and the expansion strategy. As well as being presented with the results, participants received copies of all materials used during the project. We also presented results in individual meetings with staff from the $\mathrm{MOH}$ Reproductive Health Program and the Calidad de Salud project to foster the utilization of strategies employed in the bilateral project, which includes the introduction of vasectomy in eight hospitals. Finally, in Bolivia and Honduras, we will coordinate workshops with EngenderHealth to analyze these experiences with the aim of adapting the model to their needs and applying it to those countries.

\section{CONCLUSIONS AND RECOMMENDATIONS}

The conclusions and recommendations from the study are the following:

The introduction model for vasectomy in the MOH centers proved successful.

- A high proportion of hospitals that identified vasectomy candidates finished the complete process: their surgeons attended the half-day theoretical training and completed the number of cases necessary to feel confident in their skills, as well as the satisfaction of their instructors on their surgical knowledge. The approach of requesting the identification of a vasectomy candidate as a requirement to begin training activities worked as an effective filter that eliminated training of unmotivated health teams and prevented wasting scarce resources. We recommend this practice be used, especially in countries with weak supervision systems or lacking the appropriate mechanisms to guarantee that organizations' guidelines and action plans are followed.

- The information package generated 205 vasectomy requests, enough for surgeons to perform 158 operations and complete their training. Data indicate that the effectiveness of the intervention depended more on the multiplicity of channels and sources than on any one of them in particular. Providing information on vasectomy to women immediately postpartum and giving them material to look over with their partners seems to be most important. Giving leaflets and brochures to vasectomized men to hand them out among their friends is a strategy that requires minimal effort and has a certain degree of effectiveness, as does distributing the material in waiting rooms. Although training health teams in nearby health centers was also an effective strategy, it is the most difficult and costly component to implement. We therefore recommended that teams only be trained where surgeries are performed or if costs for conducting this activity can be reduced. 
- The on-the-job training strategy was very successful. It allowed for 8 surgeons to be certified and generated enough cases for two of the hospitals to function as $\mathrm{MOH}$ training centers. The most productive unit was the Zone 19 maternity, which after certification has had four sessions with an average of 9 surgeries per session. The Zone 18 maternity has performed 15 vasectomies in four sessions, that is to say, slightly more than three per session. However, even when there are units with a volume that would allow for more rapid surgeon training, we recommend that trainees continue to have several training sessions in their own working sites, since this requires that the service delivery unit's health teams implement the educational activities. Also, the instructor's visit simultaneously works as a visit for training, supervising to reinforce the systems, and for motivating health team members. Sending surgeons to a high volume center to do their practice should only be used as a complementary measure to save on costs and shorten the training period.

- The strategy allowed for the service to be institutionalized in participating hospitals and in a sufficient quantity to allow them to serve as training centers. The four hospitals and clinics where surgeons were certified continued to provide the service after certification. These centers had 28 post-certification surgery sessions and have performed 74 vasectomies in total, slightly higher than two per session. On average, the centers have had at least one monthly session after the certification of their surgeons. We recommend that the National Reproductive Health Program and the "Calidad de Salud" program do follow-ups of these four sites, or at least on the Zone 18 and 19 and Amatitlán clinics (since the Chimaltenango hospital is included in its action plan). This will allow them to meet their goals more easily in the eight hospitals included in their action plan, by using them to facilitate the pace of training of health teams and surgeons. A way of doing this would be to carry out part of the provider training in the "Calidad en Salud" project participant hospitals.

\section{Some characteristics of the model used could be improved}

Some recommendations for making the introduction model more effective that arose during the implementation of the project were the following:

- Surgeons trained in the project recommended doing operations on Fridays after 11:00 am or on Saturday morning, in order to allow the operated men to rest over the weekend, so they do not have to ask for more than half a day off from work.

- Counseling on postoperative spermogram visits should be reinforced; virtually no patient returned three months later to have a follow-up spermogram test. Client counseling should reinforce the importance of verifying the success of the operation by means of the laboratory exam. Strategies should be put in practice to improve attendance to this check-up visit, such as giving them cards and phoning them as a reminder.

- One of the most difficult tasks in learning the no-scalpel vasectomy technique was identifying the vas deferens. Perhaps this part of training could be reinforced 
through the use of anatomical models (such as those developed by EngenderHealth). We recommend that participants practice this step on their own bodies, and suggest that those trained at the theoretical sessions (which can be given in group) practice this step on other participants or during urology practices in their hospitals.

- With regard to the promotion model, this project initially attempted to invite vasectomy accepters to a promotion training meeting, but very few showed interest. It is much more effective to take advantage of the recovery period after the procedure to invite them to collaborate by providing information to other men as well as to give them recommendations for approaching the subject and hand them communication material such as leaflets and explanatory brochures. In this project, a significant number of patients were referred by vasectomy clients, and facilitating this natural occurrence is relatively simple.

- Other successful vasectomy providers in Latin America, such as the IMSS, have a longer surgeon certification process. Those trained by the IMSS usually do between five and ten supervised procedures and then begin to provide the service to their own clients. However, they are not certified until they have performed 20 unsupervised operations and the instructor has visited them to make sure they are following the surgical protocol in an appropriate fashion. We believe this can be a good resource to strengthen the surgeon's abilities and the health team's motivation to provide the method.

\section{Characteristics of the average vasectomy acceptor in Guatemala are similar to those observed in other Latin American countries}

The average vasectomy acceptor in this project is a man that is married or living in a consensual union, between 25 and 34 years of age, with two or three children, who has more than an elementary school education, is employed, practices a religion and wishes to protect the health of his wife or partner and/or receives a medical recommendation to have a vasectomy. Although slightly younger in age, this is consistent with the characteristics of vasectomy users as determined by studies conducted 10 or more years ago in other Latin American countries: between 30 and 40 years old, married or in union, living in large cities, permanently employed, with an educational level higher than the country's average, users of other contraceptive methods, with small families and concerned with their family's well-being.

The recommendations that emerge from these findings include that service providers should be trained to discuss the option of vasectomy as a family planning method, particularly in counseling men with these characteristics. 


\section{REFERENCES}

Atkins, B.S. y T.W. Jezowski. 1983. Report on the First International Conference on Vasectomy. Studies in Family Planning Vol 14:89, 1983.

Foreit, Karen; M.P.P de Castro and E.F. Duarte Franco. 1989. The Impact of a Mass Media Advertising on a Voluntary Sterilization Program in Brazil. Studies in Family Planning, Vol 20, No. 2, pps. 107-126.

Juárez, Consuelo. 2003. Using a Systems Approach to Expand Vasectomy services: The Experience of the Instituto Mexicano del Seguro Social. Presentation made at the meeting on Vasectomy; New Evidence about a Long-Standing Method. Organized by Engender Health and Family Health International. Washington, D.C., December 4-5, 2003.

Ministerio de Salud Pública y Asistencia Social (MSPAS), INE et al. 2003. Guatemala. Encuesta Nacional de Salud Materno Infantil 2002. MSPAS, Guatemala, Octubre

Vernon, Ricardo. 1996. Operations Research on Promoting Vasectomy in Three Latin American Countries. International Family Planning Perspectives, Vol. 22, No. 1, March, PPs: 26-31 


\section{APPENDICES}

Appendix 1: “Family planning is also men’s business (La planificación familiar también es cosa de hombres)" flyer.

Appendix 2: Family planning is also men’s business (La planificación familiar también es cosa de hombres)" poster

Appendix 3: “Let’s choose as a couple (Decidamos en Pareja)” brochure

Appendix 4: Checklist used by trainers

Appendix 5: Referral Card and instructions for the client

Appendix 6: Interview questionnaire for vasectomized clients 